\title{
INHALTSVERZEICHNIS
}

\section{ABTEILUNG: Beiträge}

NORBERT ZIMMERMANN - VASILIKI TSAMAKDA

Das START-Projekt „Domitilla“. Arbeitsbericht über die Dokumentation

und Erforschung einer römischen Katakombe unter Einsatz des 3D-Laserscanners

DorotTya GÁSPÁR

Inschriften aus Pannonien; christlich oder nicht christlich?

Ivo TopaliLov

Neue archäologische Forschungen in Philippopolis (Plovdiv, Bulgarien):

Ein spätantikes (frühchristliches) Gebäude in der Alexander Puschkin-Straße

EUGENIO Russo

Riportato alla luce un pluteo frammentario della chiesa di S. Giovanni a Efeso

PHILIPP NIEWÖHNER

Die große Friedhofskirche von Milet. Vorbericht über die Ausgrabung einer neu entdeckten Transeptbasilika

Annegret Plontke-LÜning

Eine unbekannte Kirche bei Irmašly/Westazerbajdžan

II. ABTEILUNG: Literaturbericht

Reinhardt Harreither - Michael Huber - Renate Pillinger

Bibliographie zur Spätantike und Frühchristlichen Archäologie in Österreich (mit einem Anhang zum spätantik-frühchristlichen Ephesos).

2006 erschienene Publikationen und Nachträge 
